\title{
MYXOMA OF THE RIGHT ATRIUM
}

\author{
BY

\section{K. CATT, M. A. DENBOROUGH, LINDSAY GRIGG, AND GRAEME SLOMAN}

\author{
The Royal Melbourne Hospital, Victoria, Australia
}

A primary tumour of the atrium was first diagnosed ante-mortem by Kirkeby and Leren (1952), and the first successful surgical removal of a left atrial myxoma was done by Crafoord (1955). A myxoma in the right atrium is less common than in the left, and so has not received as much attention. The case that follows is of a 40-year-old woman who was admitted in severe congestive heart failure. A diagnosis of right atrial myxoma was made, the tumour was removed successfully, and she has returned to a normal life.

\section{Case Report}

The patient, a 40-year-old housewife from Yugoslavia, was admitted to hospital on December 9, 1960. She had had shortness of breath on exertion and nocturnal dyspncea for eight months. Her legs had been swollen, but she had lost 21 pounds in weight.

On examination there was peripheral cyanosis and œdema of the legs and over the sacrum. The blood pressure was 120/90 and the pulse was 80 a minute, regular, and of small amplitude. The jugular venous pressure was raised 15 centimetres and the jugular venous pulse had prominant " $a$ " and " $v$ " waves. There were no signs of cardiac enlargement. In the mitral area there was a loud pansystolic murmur and a loud sound in early diastole which was thought to be an opening snap. The first and second heart sounds were normal. A diagnosis was made of mitral valve disease with congestive heart failure and the patient was treated with digoxin and diuretics.

Three days later the condition was much improved. The œdema had almost disappeared but the jugular venous pressure was still raised. The murmur at the apex was now insignificant but the opening snap was still present. In addition, a loud pleuro-pericardial friction rub was audible at the left sternal edge and this persisted throughout her illness. The diagnosis of rheumatic mitral valve disease now seemed incorrect and constrictive pericarditis was considered, but the electrocardiogram which showed a $P$ pulmonale in leads $\mathrm{V} 1$ and $\mathrm{V} 2$ and $\mathrm{T}$ wave inversion in V1-V4 did not support this. The pleuropericardial friction rub and the right-sided electrocardiogram suggested the possibility of recurrent pulmonary emboli, and anticoagulant therapy was started.

The patient continued to improve but the physical signs remained unchanged. The temperature chart showed spikes of fever occurring every few days and the erythrocyte sedimentation rate was raised to $48 \mathrm{~mm}$. in 1 hour (Westergren). The hæmoglobin was $12.8 \mathrm{~g}$. per $100 \mathrm{ml}$. The white blood cell count was 9000 per $\mathrm{ml}$. with a normal differential count and the blood film was normal. Blood cultures and a Mantoux test $1 / 1000$ were negative and the arterial oxygen saturation and $\mathrm{pCO}_{2}$ were normal. An X-ray of the chest was thought to be normal although prominence of the right atrium was noted (Fig. 1). Phonocardiography confirmed the presence of an added sound $0.18 \mathrm{sec}$. after aortic valve closure, louder on inspiration and maximal in the fourth left intercostal space.

Eight days after admission the patient began to have occasional episodes of acute breathlessness. Five of these occurred over the next two weeks. During the only observed attack she was very weak and cyanosed with a blood pressure of $100 / 80$, but with no moist sounds audible in the chest. The pyrexia persisted and was found to respond to steroids. On the twenty-fourth day after admission two attacks of transient syncope occurred. She was cyanosed and apparently moribund during the second of these attacks. Examination soon after recovery showed pallor, moderate shortness of breath, and weakness. It was then that the 


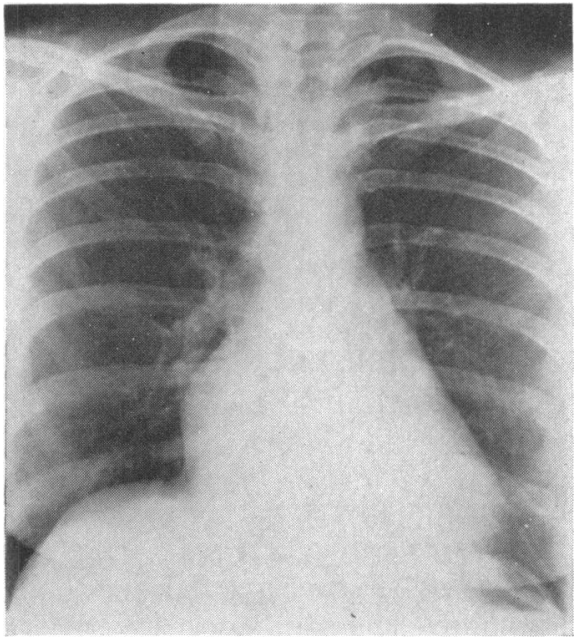

FIG. 1.-X-ray of heart before operation on right atrial myxoma.

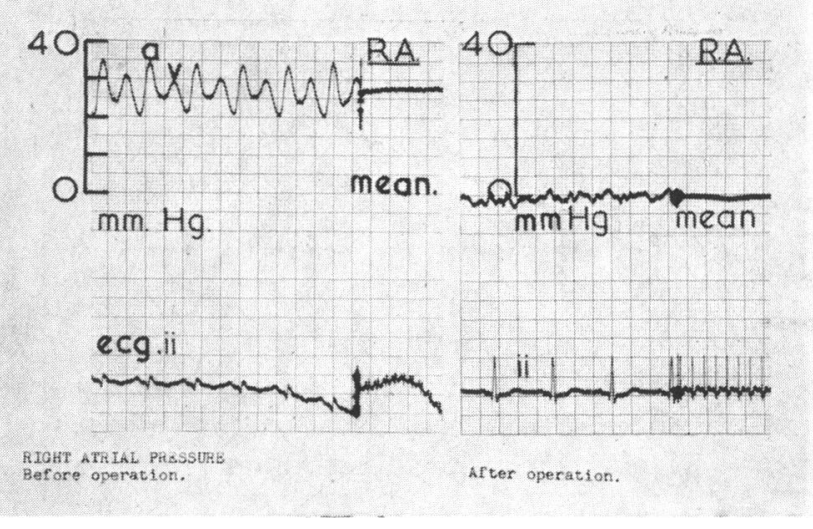

FIG. 2.-Right atrial myxoma: pressure tracings at catheterization before and after operation.

relationship between her attacks and postural change was appreciated, and a diagnosis of atrial myxoma seemed likely. Because of the P pulmonale on the electrocardiogram it was felt that the myxoma would have to be in the right atrium.

At cardiac catheterization on January 9,1961 , the catheter passed without difficulty to the pulmonary artery, in which the pressure was $20 / 4 \mathrm{~mm}$. with a mean of $17 \mathrm{~mm}$. $\mathrm{Hg}$. On screening the right atrium was seen to be considerably enlarged and it moved in an unusual fashion. A selective angiogram into the main pulmonary artery showed a normal left atrium. On withdrawal of the catheter from the right ventricle into the right atrium a diastolic gradient of $10 \mathrm{~mm}$. of mercury was recorded (Table I). The " $a$ "

TABLE I

Catheterization Data Before and After Removal of Atrial MYXOMA

\begin{tabular}{|c|c|c|c|}
\hline Site & & $\begin{array}{c}\text { Pre-operative } \\
9 / 1 / 61\end{array}$ & $\begin{array}{c}\text { Post-operative } \\
30 / 5 / 61\end{array}$ \\
\hline Right atrium .. & $\cdots$ & $\begin{aligned} a & =35 \\
v & =30 \\
x \text { trough } & =25 \\
y \text { trough } & =20 \\
\text { Mean } & =28\end{aligned}$ & $\begin{array}{r}a=0 \\
v=0 \\
\text { Mean }=0\end{array}$ \\
\hline Right ventricle & . & $20 / 10$ & $10 / 0$ \\
\hline Pulmonary artery & . & $20 / 4$ & $18 / 2$ \\
\hline
\end{tabular}

Intracardiac pressure in $\mathrm{mm}$. $\mathrm{Hg}$.

wave was $35 \mathrm{~mm}$. $\mathrm{Hg}$ and the "v" wave $30 \mathrm{~mm}$. (Fig. 2). A second angiogram was carried out with the catheter high in the right atrium and this demonstrated a large filling defect (Fig. 3). Serial blood samples showed no evidence of an intracardiac shunt.

Surgical Treatment. Operation was carried out under hypothermia on January 12, 1961 (L.G.). With the patient in a posture designed to prevent tricuspid obstruction a transverse sternum-splitting approach was made along the lower borders of the fourth ribs. The right atrium and appendage were huge. The superior vena cava, aorta, and pulmonary artery were normal but the inferior vena cava was almost one and a half times the normal diameter. The tumour could be felt in the right atrium. 


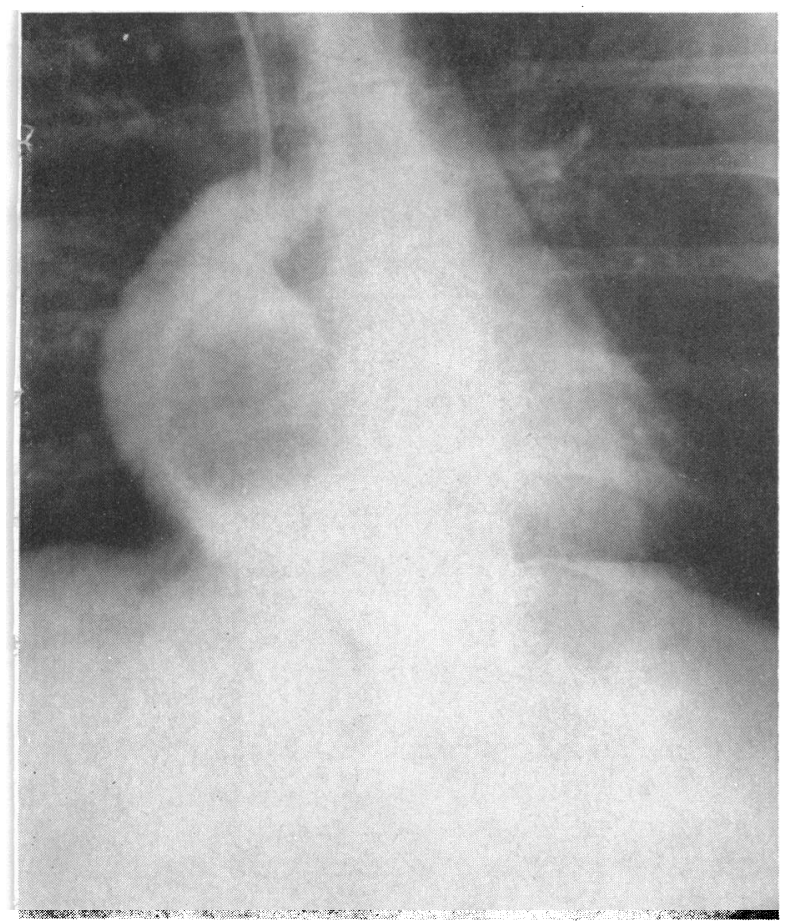

FIG. 3.-Angiocardiogram showing myxoma in right atrium.

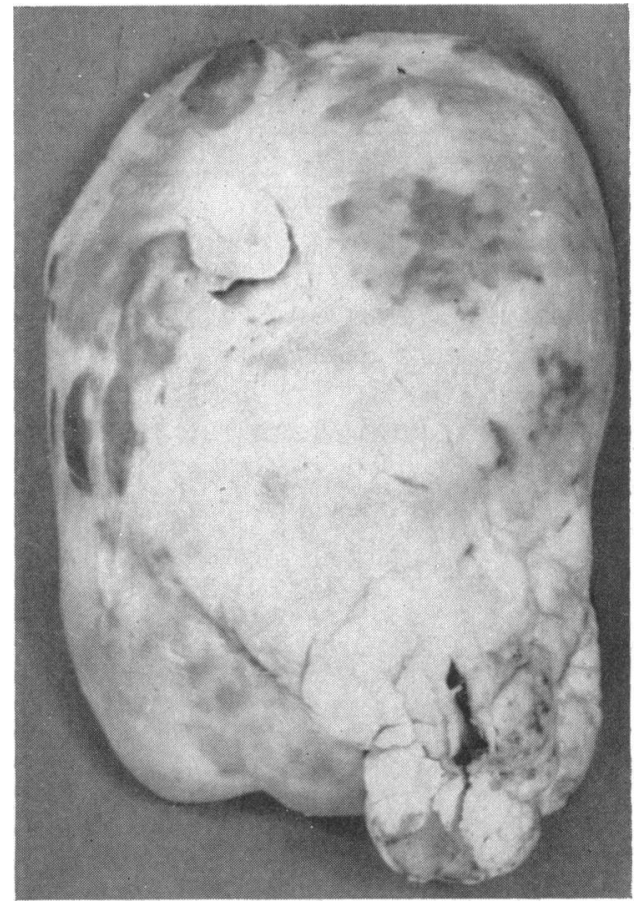

FIG. 4.-Photograph showing the myxoma after removal. It measured $7 \times 5 \times 4 \mathrm{~cm}$.

No attempt was made to explore the heart before occlusion, but the right atrium was opened over a Beck clamp. The caval snares were tightened, the heart was allowed to empty for twenty seconds and then the aorta and pulmonary artery were cross-clamped. The atriotomy was extended and the tumour prolapsed. The myxoma was removed intact by excising the origin of its pedicle from the interatrial septum, just above and behind the coronary sinus, using a specially modified dessert-spoon (Collis and Shah, 1959), which had a bag of surgical gauze sutured to it through multiple drill holes. The tricuspid valve was normal although part of the tumour had protruded through it. Another part lay in the inferior vena cava. The septal defect was sutured and the atriotomy partly closed. The inferior vena caval snare was released and as blood welled up the air was expelled and the atriotomy clamped. All snares were released and then atrial closure was completed. The heart resumed normal rhythm spontaneously after a total occlusion time of 7 minutes 45 seconds. Pericardial and chest wall closure were completed with bilateral basal thoracic drains. The postoperative convalescence was uneventful.

On discharge from hospital 16 days after operation, the patient was symptom free and the only abnormal physical sign was a raised jugular venous pressure. When she was reassessed five months later the electrocardiogram and the findings at cardiac catheterization were within normal limits (Table I).

Pathology. The tumour measured $7 \mathrm{~cm} . \times 5 \mathrm{~cm} . \times 4 \mathrm{~cm}$. (Fig. 4). Histologically it appeared to be a partly organized thrombus in a homogeneous eosinophilic matrix. In some places there were stellate fibrocytes, in others macrophages containing blood pigment and there were some newly-formed blood vessels. A well defined capsule was present.

\section{Discussion}

In spite of increasing awareness of intracardiac tumours the diagnosis is often difficult. Twelve successful operations for the removal of a tumour from the right atrium have been reported, ten from America, one from Canada, and one from Czechoslovakia (Hanlon, 1957; Krcilkova et al., 
1958; Scannell and Grillo, 1958; Coates and Drake, 1958; Ellis et al., 1958; Padhi et al., 1959; Cooley et al., 1959; Taber and Lam, 1960; Ashman et al., 1960; Campeti et al., 1960; Levinson and Kincaid, 1961). The time between the onset of symptoms and diagnosis in these patients varied from two months (Ashman et al., 1960) to eight years (Krcilkova et al., 1958), with an average of three years.

The diagnosis of right atrial myxoma has been made at thoracotomy for tricuspid stenosis (Ellis, et al., 1958), and of a fibrosarcoma of the right atrium at thoracotomy for resistant pericardial effusion (Scannell and Grillo, 1958). One patient had a laparotomy as a carcinoid tumour was suspected (Ashman et al., 1960).

The patient described here illustrates some of the difficulties that may be experienced in diagnosis. The cardiac murmurs may simulate rheumatic heart disease. The pyrexia and raised erythrocyte sedimentation rate may suggest bacterial endocarditis or myocarditis. Obstruction at the tricuspid valve may appear to be due to tricuspid stenosis or Ebstein's disease. Recurrent attacks of shortness of breath with a friction rub on auscultation may simulate recurrent pulmonary emboli.

Right atrial myxoma may also mimic constrictive pericarditis and it may cause a variable right 9 to left shunt through a foramen ovale (Coates and Drake, 1958). Recently it has been described in association with polycythæmia with a raised platelet count (Levison and Kincaid, 1961), which regressed following removal of the tumour.

A critical factor in establishing the diagnosis is the relationship between attacks of shortness of breath or syncope and changes in posture. Furthermore, when shortness of breath is produced by the myxoma obstructing the tricuspid valve no crepitations are heard on auscultation of the lungs.

Cardiac exploration prior to occlusion was avoided to prevent emboli coming from the tumour. Under hypothermia removal of the myxoma was simple and satisfactory, and induced cardiac arrest was unnecessary.

\section{Summary}

A 40-year-old woman presented with severe congestive heart failure due to a myxoma of the right atrium. The tumour was removed under hypothermia and the patient is now well.

We would like to thank Professor R. R. H. Lovell, under whose care this patient was admitted, for his encouragement.

\section{References}

Ashman, H., Zaroff, L. I., and Baronofsky, I. (1960). Amer. J. Med., 28, 487.

Campeti, F. L., Mahoney, E. B., and Yu, P. N. (1960). Circulation, 22, 730.

Coates, E. O., and Drake, E. H. (1958). New Engl. J. Med., 259, 165.

Collis, J. L., and Shah, N. J. (1959). Thorax, 14, 232.

Cooley, D. A., Morris, G. C., and Attar, S. (1959). Arch. Surg., 78, 410.

Crafoord, C. (1955). In Proceedings of the International Symposium on Cardiovascular Surgery, held at the Henry Ford Hospital, Detroit, Michigan, March 1955 (edited by C. R. Lam). Philadelphia, W. B. Saunders, p. 202.

Ellis, F. H., Mankin, H. T., and Burchell, H. B. (1958). Med. Clin. N. Amer., 42, 1087.
Hanlonn, C. R. (1957). In Discussion of paper by Bahnson, H. T., Spencer, F. C., Andrus, E. C. Ann. Surg., 145, N 925.

Kirkeby, K., and Leren, P. (1952). Acta med. Scand., 143, 384.

Krcilkova, M., Musil, J., Navratil, J., and Olejnik, O. (1958). Thorax, 13, 173.

Levinson, J. P., and Kincaid, O. W. (1961). New Engl. J. Med., 264, 1187.

Padhi, R. K., Kelly, H. G., and Lynn, R. B. (1959). Canad. J. Surg., 2, 414.

Scannell, J. G., and Grillo, H. C. (1958). J. thorac. Surg., 35, 23.

Taber, R. E., and Lam, C. R. (1960). J. thorac. cardiovasc. Surg., 40, 337. 